\title{
INFLUENCE OF MEDIUM ON CORROSION AND MICROSTRUCTURAL PROPERTIES OF K110 TOOL STEEL FOR COLD WORK
}

\author{
Sandra BRAJČINOVIĆ, Anita BEGIĆ HADŽIPAŠIĆ, Ljerka SLOKAR BENIĆ \\ University of Zagreb, Faculty of Metallurgy, Sisak, Republic of Croatia, EU \\ smitic@simet.unizg.hr, begic@simet.unizg.hr, slokar@simet.unizg.hr
}

https://doi.org/10.37904/metal.2020.3558

\begin{abstract}
This paper presents the results of testing the corrosion behaviour of $\mathrm{K} 110$ tool steel for cold work in industrial emulsion medium (Lenox Band-Ade semi-synthetic oil + water, in a ratio of $1: 10$ ), water and $3.5 \% \mathrm{NaCl}$ medium. Using the method of electrochemical impedance spectroscopy (EIS) and Tafel extrapolation, electrochemical measurements were performed in order to determine the corrosion parameters. After polarization measurements, the surface of the sample was examined with an optical microscope. Tafel extrapolation of the polarization curves revealed that the tested tool steel showed the lowest corrosion rate in the Lenox Band-Ade emulsion medium and the highest in the medium of $3.5 \% \mathrm{NaCl}$. The obtained results were confirmed by the method of electrochemical impedance spectroscopy, where the lowest charge transfer resistance was registered in the $3.5 \% \mathrm{NaCl}$ medium, which indicates the fact that the thinnest oxide layer was formed in tested medium, which has a very weak protective role in the corrosion process. Metallographic analysis of the sample surface after polarization measurements in $3.5 \% \mathrm{NaCl}$ medium indicates the occurrence of pitting corrosion caused by the action of aggressive chloride ions from the solution, which caused the destruction an already weak passive layer on the metal surface. At the same time, chloride ions from the acid medium attack more aggressively the matrix of the metal base of the tool steel, in contrast to the precipitated carbides on the sample surface.
\end{abstract}

Keywords: Tool steel for cold work, corrosion rate, impedance, microstructure

\section{INTRODUCTION}

Steel is nowadays an irreplaceable material that enables the development of modern society. Alloying affects the properties of steel, which is why steel as a product has found application in various industrial plants and industries. The basic properties of steel are determined by the chemical composition, microstructure, shape and dimensions of the products [1,2]. Tool steels are particularly exposed to wear, high forces and stresses, which requires high toughness. Tool steels are applied in the heat-treated state, ie they are usually hardened and tempered. Basic properties such as wear resistance are achieved by a martensitic microstructure with a high carbide content [3]. In addition to properties such as wear resistance and toughness, tool steels are often required to have dynamic durability, resistance to oxidation and corrosion, resistance to hot cracking and tempering. Tool steels for cold work are used at operating temperatures up to $200^{\circ} \mathrm{C}$. Depending on the properties of the tool steel to be achieved, alloying elements such as chromium, tungsten, molybdenum and vanadium are added [4]. Tool steel $\mathrm{K} 110$ belongs to the category of high-alloy ledeburite steels and is included in the category of D2 class. The chemical composition of this type of steel has been modified in terms of lowering the carbon content with the addition of alloying elements of molybdenum and vanadium, in order to achieve the best possible toughness. Tool steel K110 is a dimensionally stable steel, very high resistance to abrasive and adhesive wear due to the high content of hard carbides in the metal grid. It is considered a very good base material for PVD/CVD coating and is suitable for nitriding due to its secondary hardening properties. It is used for high-strength cutting tools, woodworking tools, cutting shears, thread rolling tools, drawing tools, 
deep drawing and cold extrusion tools, measuring instruments, etc. [5]. Since corrosion shortens tool life [6,7], the influence of Lenox Band-Ade emulsion, water and $3.5 \% \mathrm{NaCl}$ on the corrosion and microstructural properties of $\mathrm{K} 110$ cold steel tool steel was studied in this paper.

\section{MATERIALS AND METHODS}

A sample of tool steel for cold work marked $\mathrm{K} 110$ was used to examine the influence of media and microstructure on the corrosion resistance of tool steel. The chemical composition of the tested tool steel is shown in Table 1.

Table 1 Chemical composition of K110 tool steel for cold work (wt\%)

\begin{tabular}{|c|c|c|c|c|c|c|c|c|c|}
\hline $\mathbf{C}$ & $\mathbf{S i}$ & $\mathbf{M n}$ & $\mathbf{C r}$ & $\mathbf{M o}$ & $\mathbf{N i}$ & $\mathbf{V}$ & $\mathbf{W}$ & Co & $\mathbf{F e}$ \\
\hline 1.55 & 0.30 & 0.30 & 11.30 & 0.75 & - & 0.75 & - & - & balance \\
\hline
\end{tabular}

Tool steel K110 contains a high proportion of carbon and chromium, where chromium is considered as main alloying element. In combination with carbon, it has the ability to form carbides, and the most common type of carbide is $\mathrm{Cr} 23 \mathrm{C} 6$ and $\mathrm{Cr} 7 \mathrm{C} 3$. Corrosion resistance increases with the increase of chromium content, because chromium carbides increase the wear resistance, which increases the durability and lifetime of cutting tools. Vanadium is a strong carbide-forming agent that can be used for refinement of primary austenitic grain [2]. Molybdenum in combination with other alloying elements increases the hardenability and together with chromium increases the resistance of steel to general and pitting corrosion. Silicon does not produce carbides, but acts as a deoxidant, raising the yield strength and increasing the hardenability of steel. Manganese is used as a deoxidizer and desulfurizer during steel production [3]. Samples of tool steel for electrochemical measurements were prepared by hot pressing into a conductive mass and machine ground and polished, after which they were washed in distilled water and degreased in ethanol. The corrosion potential determination method $E_{\text {corr }}$ electrochemical impedance spectroscopy (EIS) and the Tafel extrapolation method were used to obtain data on the corrosion behaviour of the samples. For these measurements, a three-electrode glass cell was used in which the working electrode (tested metal), the reference electrode (saturated calomel electrode) and the counter-electrode (Pt-electrode) were placed. The central part of the electrochemical testing system is the potentiostat/galvanostat device which establishes and maintains the desired potential difference between the working and reference electrode, but at the same time registers the current between the working electrode and the counter electrode. Industrial emulsion (Lenox Band-Ade semi-synthetic oil+water, ratio 1:10), water and medium $3.5 \% \mathrm{NaCl}$ were used as working medium in electrochemical experiments. Stabilization of the open circuit potential $E_{o c p}$ was performed at room temperature $T=(19 \pm 2)^{\circ} \mathrm{C}$ and for 1800 seconds. Electrochemical impedance spectroscopy (EIS) was performed in the frequency range from $100 \mathrm{kHz}$ to 10 $\mathrm{mHz}$ with a sinusoidal voltage amplitude of $5 \mathrm{mV}$. Impedance parameters were analyzed by ZSIMPWin 3.21 software using the appropriate model of the electrical circuit $R(Q(R(Q R)))$. The Tafel extrapolation method was performed using potentiodynamic polarization in the potential range from $-250 \mathrm{mV}$ to $+250 \mathrm{mV}$ vs $E_{\text {corr, }}$, with a potential change rate of $5 \mathrm{mV} \mathrm{s}^{-1}$. Corrosion parameters were determined by PowerCorrTM software using the Tafel extrapolation method and Faraday's laws. The sample was observed on an optical microscope with a digital camera and a system for automatic image processing before and after corrosion in the examined media [8]. In order to highlight the microstructure of the $\mathrm{K} 110$ tool steel for cold work, one sample was metallographically prepared and etched in $0.5 \%$ Nital.

\section{RESULTS AND DISCUSION}

Figure 1 shows the time dependences of the open circuit potential for the tested tool steel sample in different media (Lenox Band-Ade emulsion, water, 3.5\% NaCl). The tested sample in the mentioned media quickly reaches an open circuit potential. In doing so, it is important to note that the tool steel in the Lenox Band-Ade 
emulsion medium tends towards positive values of the electrode potential, which means that the working electrode is more stable compared to the test in water and $3.5 \% \mathrm{NaCl}$. In water and medium $3.5 \% \mathrm{NaCl}$ the open circuit potentials are expressed in negative values. Negative values indicate the presence of corrosion, ie the instability of the electrode, which causes the sample dissolution. The reason for this deviation is that the Lenox Band-Ade emulsion medium contains inhibitors that prevent further dissolution of the sample, ie it is possible to create a layer of better protective properties on the sample.

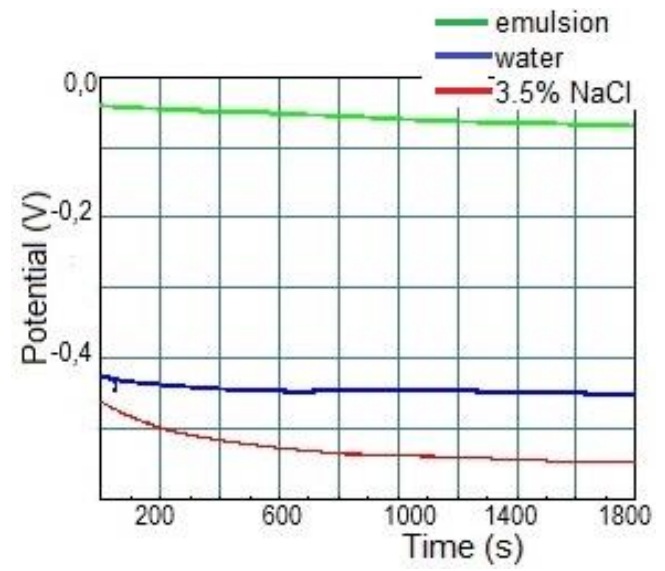

Figure 1 Time dependence of open circuit potential for $\mathrm{K} 110$ tool steel for cold work in tested media

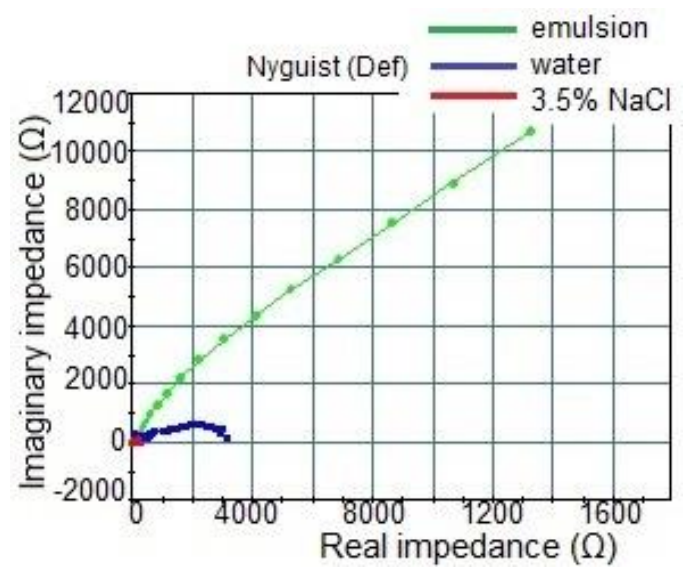

Figure 2 The comparative view of Nyquist's EIS diagrams obtained for $\mathrm{K} 110$ tool steel in tested media

The result of electrochemical impedance spectroscopy is shown by the Nyquist diagram (Figure 2), which represents the dependence of the imaginary impedance component in relation to the real component [9]. By modelling the EIS diagrams, the impedance parameters electrolyte resistance $R_{e l}$, oxide layer resistance $R_{o x}$, constant phase element of double layer $Q_{d l}$, surface heterogeneity measure $n$ and charge transfer resistance $R_{c t}$ were obtained and are listed in Table 2.

Table 2 Impedance parameters of K110 tool steel for cold work obtained in tested media

\begin{tabular}{|c|c|c|c|c|c|c|c|c|}
\hline Medium & $\begin{array}{c}E_{\text {corr vs. SCE }}(\mathrm{mV}) \\
\end{array}$ & $\begin{array}{c}\begin{array}{c}\mathbf{R e l}_{\mathrm{el}} \\
\left(\Omega \mathrm{cm}^{2}\right)\end{array}\end{array}$ & $\begin{array}{c}Q_{\mathrm{dl}} \cdot 10^{6} \\
\left(\Omega^{1} \mathbf{s}^{n} \mathbf{c m}^{-2}\right)\end{array}$ & $n$ & $\begin{array}{c}\mathbf{R}_{\mathrm{ox}} \\
\left(\Omega \mathrm{cm}^{2}\right)\end{array}$ & $\begin{array}{c}Q_{\mathrm{dll}} \cdot 10^{6} \\
\left(\Omega^{1} \mathbf{s}^{n} \mathbf{c m}^{-2}\right)\end{array}$ & $\mathbf{n}$ & $\begin{array}{c}\mathbf{R}_{\mathrm{ct}} \\
\left(\Omega \mathrm{cm}^{2}\right)\end{array}$ \\
\hline $\begin{array}{l}\text { Lenox Band- } \\
\text { Ade emulsion }\end{array}$ & -70.2 & 66.02 & 182.3 & 0.70 & 17530.0 & 507.2 & 0.76 & 41720.0 \\
\hline Water & -453.0 & 286.5 & 55.88 & 0.50 & 1552.0 & 409.5 & 0.65 & 1504.0 \\
\hline $3.5 \% \mathrm{NaCl}$ & -548.0 & 8.8 & 1182.0 & 0.70 & 15.92 & 687.8 & 0.68 & 260.8 \\
\hline
\end{tabular}

In Figure 2, Nyquist impedance representations in the examined media are in the form of depressive semicircles, which is characteristic of solid electrodes. From the data in Table $\mathbf{2}$ it can be seen that the tested tool steel in the Lenox Band-Ade emulsion medium showed far higher oxide resistance $R_{o x}$ and charge transfer resistance $R_{c t}$ than that in water and $3.5 \% \mathrm{NaCl}$. The obtained results indicate that by measuring the impedance in the Lenox-Band emulsion on a sample of tool steel, an oxide layer of greater thickness was formed, slowing down the corrosion processes. The formation of a thicker oxide layer enables a better protective role on the surface of the tested steel, which prevents the possibility of corrosion. If we compare the results of $R_{o x}$ and $R_{c t}$ obtained for testing tool steel in water and $3.5 \% \mathrm{NaCl}$, it can be seen that the registered values for the medium of $3.5 \% \mathrm{NaCl}$ are significantly lower. Namely, the oxide layer created on the sample during exposure to $3.5 \% \mathrm{NaCl}$ is not compact enough and there is no protective barrier that can prevent further penetration of aggressive ions from the solution. Furthermore, it can be seen from Table 2 that the tested tool 
steel showed the highest value of $Q_{d l}$ in the medium of $3.5 \% \mathrm{NaCl}$. The constant phase element of double layer $Q_{d l}$ is a combination of properties related to the state of the surface and the active substances. Namely, in the presence of chloride ions, the passive film on the steel surface deteriorates and the steel spontaneously corrodes. After the passive film is destroyed, the electrical resistance and the presence of oxygen control the corrosion rate $[4,7]$. The results obtained by the EIS method coincide with the corrosion parameters obtained by the Tafel extrapolation method. The polarization curves of the tested tool steel sample in emulsion, water and $3.5 \% \mathrm{NaCl}$ are shown in Figure 3. The obtained results are shown graphically in semi - logarithmic form $(E-\log I)$ where the current density is on the $\mathrm{x}$ - axis and the potential is on the $\mathrm{y}$ - axis. Potentiodynamic polarization in the potential range from $-250 \mathrm{mV}$ to $+250 \mathrm{mV}$ vs. $E_{\text {corr }}$ was performed for the purpose of determining the corrosion parameters (corrosion potential $E_{\text {corr, }}$ corrosion rate $v_{\text {corr, }}$ anode slope $b_{a}$ and cathode slope $b_{c}$, which are listed in Table 3.

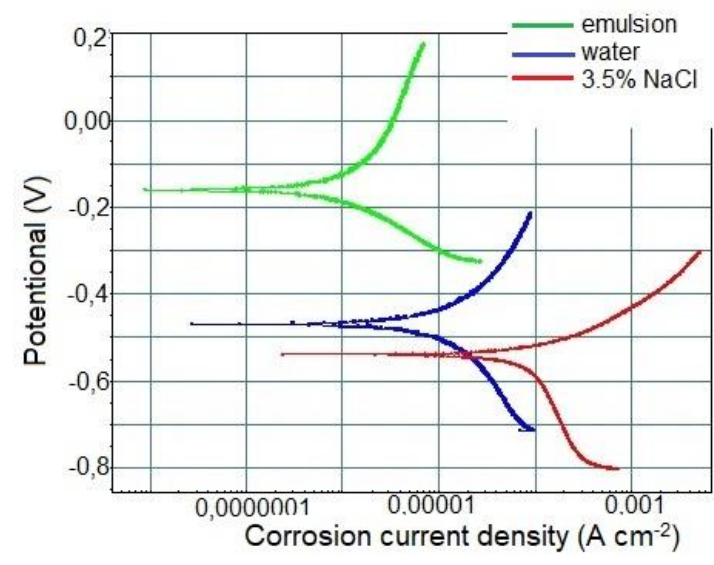

Figure 3 Polarization curves of $\mathrm{K} 110$ tool steel for cold work obtained in tested media

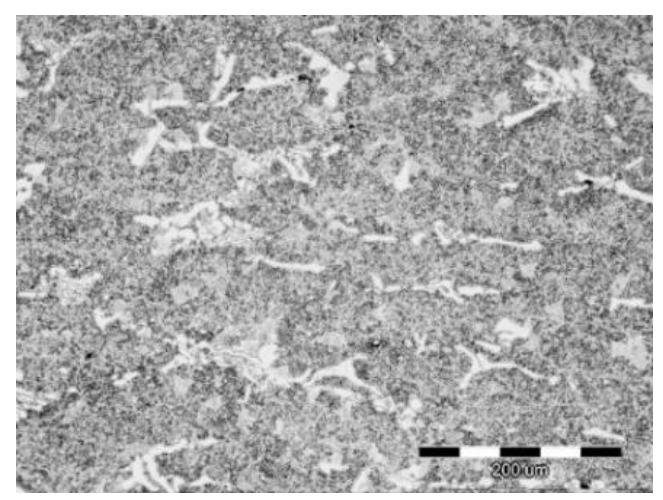

Figure 4 Microstructure of $\mathrm{K} 110$ tool steel for cold work after etching in Nital

Table 3 Corrosion parameters of tested tool steel in tested media

\begin{tabular}{|c|c|c|c|c|}
\hline Medium & $\begin{array}{c}E_{\text {corr Vs. SCE }} \\
(\mathbf{m V})\end{array}$ & $\begin{array}{c}\boldsymbol{b}_{\boldsymbol{a}} \\
\left(\mathbf{m V ~ d e c}^{-1}\right)\end{array}$ & $\begin{array}{c}\boldsymbol{b}_{\boldsymbol{c}} \\
\left(\mathbf{m V ~ d e c}^{-1}\right)\end{array}$ & $\begin{array}{c}\boldsymbol{v}_{\text {corr }} \\
\left(\mathbf{m m ~ g o d}^{-1}\right)\end{array}$ \\
\hline Lenox Band-Ade emulsion & -161.2 & 578.1 & 181.9 & 0.023 \\
\hline Water & -469.2 & 514.9 & 646.6 & 0.438 \\
\hline $3.5 \% \mathrm{NaCl}$ & -538.0 & 156.1 & 4909.1 & 2.575 \\
\hline
\end{tabular}

In Figure 3 it can be seen that the polarization curve of the tested tool steel in the emulsion is shifted to the left, which indicates that the current density values are less than is the case for the tested sample in water and $3.5 \% \mathrm{NaCl}$. For the tested tool steel in the Lenox Band-Ade emulsion, the lowest value of the corrosion rate $v_{\text {corr }}$ was registered, while the highest value of the corrosion rate $v_{\text {corr }}$ was registered in the medium of $3.5 \%$ $\mathrm{NaCl}$. Such results are expected given that $3.5 \% \mathrm{NaCl}$ medium contains chloride ions that aggressively destroy the metal surface. The Lenox Band-Ade emulsion is used in practice as a coolant in metal cutting machines and contains a sufficient amount of inhibitors to prevent further formation of corrosion products. Based on the obtained results, it can be concluded that the tested tool steel K110 is more stable in the Lenox Band-Ade emulsion compared to water and medium 3.5\% NaCl. For the purpose of analyzing the microstructure of the tested tool steel, the sample was observed using an optical microscope after etching in Nital (Figure 4). The microstructure and condition are determined by heat treatment and shaping processes. The primary structure of tool steel for cold work is ledeburite. Ledeburite steels after quenching and low tempering achieve the structure of martensite + secondary carbides. It is known from the literature that Nital can be used to show the 
distribution of carbides in tool steel for cold work, where the carbides stand out in white and the matrix is dark [8]. Furthermore, Figure 5 shows metallographic images of a sample of K110 tool steel for cold work before and after exposure to certain media.

a)

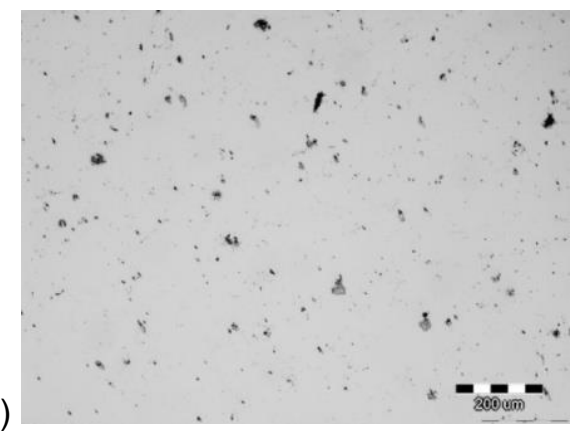

c)

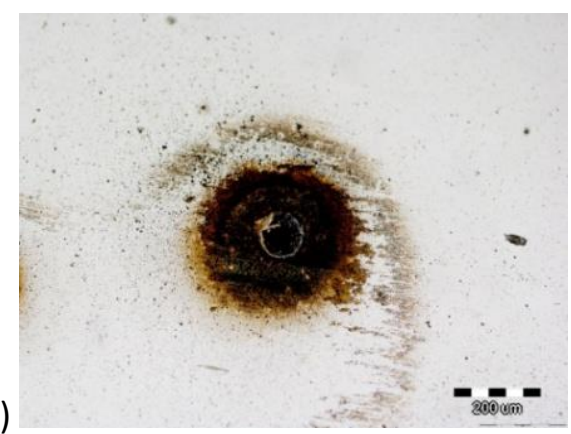

b)

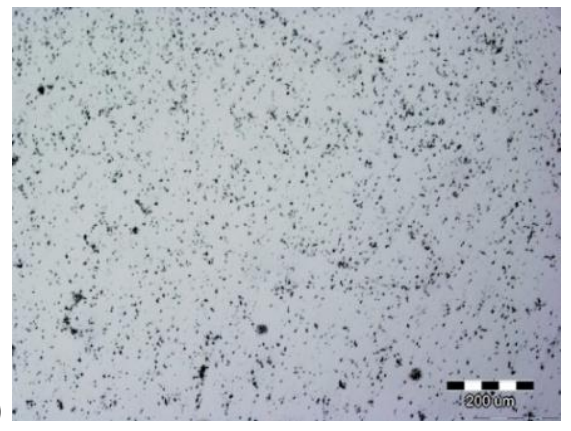

d)

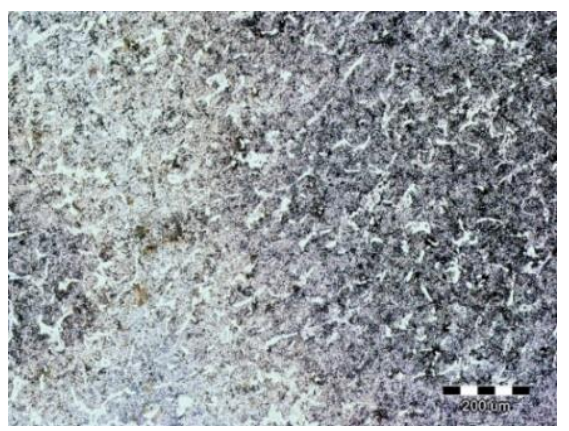

Figure 5 Microstructure of K110 tool steel for cold work (magnification 100x): a) no media, b) Lenox BandAde emulsion, c) water and d) $3.5 \% \mathrm{NaCl}$

On the surface of the sample (Figure 5a), inclusions distributed throughout the cross-section were observed. After electrochemical tests in the emulsion medium, water and $3.5 \% \mathrm{NaCl}$, microstructural changes are visible in tool steel K110, which indicate a slight oxidation of the sample surface. Lenox Band-Ade emulsion contains inhibitors, which reduces the corrosion rate of the tested steel. After exposing the sample to water and 3.5\% $\mathrm{NaCl}$, corrosion products were recorded. The sample exposed to water showed local, ie pitting corrosion in the form of pits (Figure 5c), while the sample exposed to $3.5 \% \mathrm{NaCl}$ showed more pronounced destruction of the material and only partially, along the edge of the sample. The behaviour of steel in aqueous solutions depends on the extent to which a thin protective layer of oxide will be formed, which will prevent further electrochemical reactions and protect the material from aggressive corrosive media [9]. According to Figure $5 \mathrm{~d}$, it can be seen that the surface of the sample exposed in $3.5 \% \mathrm{NaCl}$ medium was significantly corroded due to the aggressiveness of chloride ions. Aggressive chloride ions promote the destruction of the passive layer on the surface of the material and are deposited in the destroyed pits, which leads to a deeper destruction of the material [10]. The occurrence of pitting corrosion is most often associated with local inhomogeneities in the structure of the material and with the chemical composition of the material (ratio of alloying elements). When the sample is exposed to electrolytes such as aqueous solutions, microelectrolysis occurs due to the potential difference of individual areas in the structure. The consequences are manifested in the formation of solid corrosion products, eg hydrated iron oxides [11]. The resistance of steel to oxidation at ordinary and elevated temperatures and corrosion resistance is significantly improved by the addition of chromium. Chromium creates an insoluble surface film (layer) that prevents further diffusion of oxygen to the surface and prevents the oxidation of iron in the alloy matrix. However, it is dissolved by hydrochloric acid and perished as an anode in an alkaline medium. Corrosion-resistant steels in aggressive environments usually contain $12 \%$ chromium with manganese and nickel. However, the tested tool steel does not contain nickel and thus insufficient corrosion resistance is ensured [12]. 


\section{CONCLUSIONS}

By the electrochemical measurements the corrosion resistance of tool steel K110 for cold work in industrial emulsion medium (Lenox Band-Ade semi-synthetic oil + water, in a ratio of $1: 10$ ), water and $3.5 \% \mathrm{NaCl}$ was tested. After potentiodynamic polarization of the tool steel, higher values of the corrosion rate in water and $3.5 \% \mathrm{NaCl}$ were obtained compared to the medium of Lenox Band-Ade emulsion. From the impedance parameters obtained by modelling the EIS spectrum, it can be seen that the tested tool steel in the medium of Lenox Band-Ade emulsion showed far higher resistance to charge transfer $R_{c t}$ compared to water and 3.5\% $\mathrm{NaCl}$, which means that a thicker surface oxide layer was formed on the sample, which has a protective role in the corrosion process. Metallographic analysis of the sample surface after polarization measurements in $3.5 \% \mathrm{NaCl}$ medium indicates the occurrence of pitting corrosion caused by the action of aggressive chloride ions from the solution, which caused the destruction of the passive layer on the metal surface. At the same time, chloride ions from the acid medium attack the matrix of the metal base of the tool steel more aggressively, in contrast to the precipitated carbides on the sample surface. According to the obtained results, it can be concluded that the tested tool steel is not suitable for use in conditions where it would be in contact with $3.5 \%$ $\mathrm{NaCl}$.

\section{ACKNOWLEDGEMENTS}

\section{Investigations were performed within the research topic "Design and Characterization of Innovative Engineering Alloys", Code: FPI-124-2019-ZZB funded by University of Zagreb and infrastructural scientific project: Center for Foundry Technology, Code: KK.01.1.1.02.0020 funded by European Regional Development Fund.}

\section{REFERENCES}

[1] ROBERTS, G., KRAUSS, G., KENNEDY, R. Tool Steels, 5th ed., ASM International, Materials Park, 1998.

[2] KOŽUH, S. Specijalni čelici, Skripta, Sveučilište u Zagrebu Metalurški fakultet, Sisak, 2010.

[3] BRYSON, W. E. Heat selection and application of tool steels, 2nd Edition, Hanser Publications, Cincinnati, 2013.

[4] KIM. H., KANG, J., SON, D., LEE, T., CHO, K. Evolution of carbides in cold-work tool steels, Materials Characterization. 2015, vol. 107, pp. 376-385.

[5] https://www.bohler.hr/hr/products/k110/[viewed 2020-02-27].

[6] STUPNIŠEK-LISAC, E. Korozija i zaštita konstrukcijskih materijala, Sveučilište u Zagrebu Fakultet kemijskog inženjerstva i tehnologije, Zagreb, 2007.

[7] Hilti Corporation, Corrosion handbook, Schaan, Liechtenstein, 2015. [online] [viewed 2020-02-27] Available from: https://www.hilti.co.za/content/dam/documents/pdf/meta-moza/Hilti CorrosionHandbook Tech\%20Manual 10 2015.pdf

[8] BRAJČINOVIĆ, S., BEGIĆ HADŽIPAŠIĆ, A., MEDVED, J., KOŽUH, S. Influence of medium on corrosion and microstructural properties of HTCS-130 tool steel for hot work, In: 18th International Foundrymen Conference. Sisak: University of Zagreb Faculty of Metallurgy, 2019, pp. 188-205.

[9] GASSAMA, D., AZIZ DIAGNE, A., YADE, I., FALL, M., FATY, S. Investigations on the corrosion of constructional steels in different aqueous and simulated atmospheric environments, Bulletin of the Chemical Society of Ethiopia. 2015, vol.29, pp. 299-310.

[10] FONG-YUAN, M. Corrosive Effects of Chlorides on Metals, Department of Marine Engineering, NTOU Republic of China (Taiwan), 2012.

[11] BOHNI, H. Localized Corrosion of Passive Metals, ed. R. W. Revie, Uhlig's Corrosion Handbook.John Wiley and Sons, Inc., New York, 2000., pp. 173-190.

[12] TOLILOPE LOTO, R. Pitting corrosion evaluation and inhibition of stainless steels: A review, Journal of Materials and Environmental Science. 2015, vol. 6, no. 2, pp. 2750-2762. 